\title{
High IKZF1/3 protein expression is a favorable prognostic factor for survival of relapsed/refractory multiple myeloma patients treated with lenalidomide
}

\author{
Maryam Pourabdollah', Mohammad Bahmanyar ${ }^{1}$, Eshetu G. Atenafu², Donna Reece ${ }^{3}$, Jian Hou ${ }^{4}$ \\ and Hong Chang ${ }^{1,5^{*}}$
}

\begin{abstract}
The aim of this study is to assess nucleoprotein expression of IKZF1/3 in patients with relapsed/refractory multiple myeloma (MM) who received lenalidomide-based therapy and correlated them with their clinical outcomes. A total of 50 patients diagnosed with MM were entered in the study with the median follow-up of 86.4 months. By immunohistochemistry (IHC), IKZF1 and IKZF3 were expressed in 72 and 58\% of the cases, respectively. IKZF1 and IKZF3 expressions were associated with longer median progression free survival $(P=0.0029$ and $P<0.0001)$ and overall survival $(P=0.0014$ and $P<0.0001)$. IKZF3 expression also appears predicted a favorable response to the lenalidomide-based therapy.
\end{abstract}

It has been demonstrated that lenalidomide causes selective degradation of IKZF1 (ikaros) and IKZF3 (aiolos) which are two essential transcription factors for myeloma cell proliferation $[1,2]$. This anti-proliferative effect is mediated by downregulation of c-Myc and interferon regulatory factor 4 (IRF4) [3]. In particular, IKZF3 regulates expression of IRF4 which is linked with lenalidomide activity [4-6]. However, the clinical relevance of IKZF1/IKZF3 expressions in myeloma patients has not been established. Thus, we examined nuclear expression of IKZF1/3 and its correlation with clinical outcomes in patients with relapsed/refractory MM who received lenalidomide therapy.

A total of 50 patients diagnosed with $\mathrm{MM}$ in our institution were entered in the study. All had received lenalidomide-based therapy (lenalidomide plus dexamethasone) after relapse. The median follow-up after diagnosis was 7.2 years. The relevant clinical and laboratory features are summarized in Table 1.

\footnotetext{
* Correspondence: hong.chang@uhn.ca

'Department of Laboratory Medicine and Pathobiology, University of Toronto, Toronto, Canada

${ }^{5}$ Department of Laboratory Hematology, University Health Network, 200

Elizabeth Street, 11E-413, Toronto, ON M5G 2C4, Canada

Full list of author information is available at the end of the article
}

CD138 and IKZF1/3 immunohistochemical (IHC) staining were performed on the bone marrow aspiration/biopsy specimens taken before starting lenalidomide. CD138 positive myeloma cell aggregates (Additional file 1: Figure S1B) were examined for IKZF1/3 expression (Additional file 1: Figure S1C, D). H-score method (range 0-300) according to staining intensity and percentage of myeloma cells was applied. The median $\mathrm{H}$ scores for IKZF1 and IKZF3 were 150 and 200, respectively, and high or low expression was based on above or below the median H-score (Fig. 1a).

Of the $50 \mathrm{MM}$ cases, IKZF1 and IKZF3 were expressed in 36 (72\%) and 29 (58\%) cases, respectively. Twenty-eight of 29 cases (97\%) with high IKZF3 expression also showed IKZF1 positivity $(P<0.0001)$. High IKZF3 $(P=0.0025)$, but not IKZF1 expression $(P=0.094)$ was strongly correlated with clinical response (Fig. 1b). Patients with high IKZF1 or IKZF3 expression showed longer PFS (median 22.6 vs. 6.3 months, $P=0.0029$; or 43.2 vs. 3.7 months; $P<0.0001$ ) and OS (median 44.3 vs. 12.1 months, $P=0.0014$; or 47 vs. 12.1 months; $P<0.0001$ ) (Fig. 1c-f), respectively. In addition, the group with both high IKZF1/3 expression was associated with longer PFS (median 31.8 vs. 3.9 months, $P<0.0001$ ) 
Table 1 Clinical and laboratory features of MM patients treated with lenalidomide

\begin{tabular}{|c|c|c|c|c|c|c|c|}
\hline Clinical feature & $\begin{array}{l}\text { Total } \\
(n=50)\end{array}$ & $\begin{array}{l}\text { IKZF1 high } \\
\text { expression } \\
(n=36)\end{array}$ & $\begin{array}{l}\text { IKZF1 low } \\
\text { expression } \\
(n=14)\end{array}$ & $P$ value & $\begin{array}{l}\text { IKZF3 high } \\
\text { expression } \\
(n=29)\end{array}$ & $\begin{array}{l}\text { IKZF3 low } \\
\text { expression } \\
(n=21)\end{array}$ & $P$ value \\
\hline $\operatorname{Sex}(M / F)$ & $31 / 19$ & $23 / 13$ & $8 / 6$ & 0.6590 & $19 / 10$ & $12 / 9$ & 0.5471 \\
\hline Age (year), median (range) & $59(41-75)$ & $57(41-73)$ & $59(45-75)$ & 0.6416 & $57(41-69)$ & $59(44-75)$ & 0.3105 \\
\hline International staging system, no. (\%) & & & & 0.1785 & & & 0.1448 \\
\hline I & $24(48)$ & $14(38.89)$ & $10(71.43)$ & & $11(37.93)$ & $13(61.90)$ & \\
\hline$\|$ & $18(36)$ & $14(38.89)$ & $4(28.57)$ & & $11(37.93)$ & 7 (33.33) & \\
\hline III & $5(10)$ & $5(13.89)$ & $0(0)$ & & $5(17.24)$ & $0(0)$ & \\
\hline NA & $3(6)$ & $3(8.33)$ & $0(0)$ & & $2(6.90)$ & $1(4.76)$ & \\
\hline $\begin{array}{l}\text { Hemoglobin concentration }(\mathrm{g} / \mathrm{L}) \text {, } \\
\text { median (range) }\end{array}$ & $105(76-147)$ & $106(76-147)$ & $103(86-132)$ & 0.6027 & $104(76-147)$ & $107(85-141)$ & 0.3121 \\
\hline Calcium (mmol/L), median (range) & $2.25(1.98-2.57)$ & $2.26(1.98-2.57)$ & $2.23(2-2.55)$ & 0.8162 & $2.25(1.98-2.57)$ & $2.25(2-2.55)$ & 0.7160 \\
\hline Creatinine ( $\mu \mathrm{mol} / \mathrm{L})$, median (range) & $76(32-360)$ & $86(40-360)$ & $67.58(32-126)$ & 0.0569 & $88(57-360)$ & $66(32-126)$ & 0.0072 \\
\hline $\begin{array}{l}\text { Having lytic lesions, number of } \\
\text { patients (\%) }\end{array}$ & $27(54)$ & $18(50)$ & $9(64.29)$ & 0.3628 & $12(41.38)$ & $15(71.43)$ & 0.0354 \\
\hline B2-microglobulin (mg/L) & $3.08(0.51-16.76)$ & $3.50(0.51-16.76)$ & $2.96(1.35-5.16)$ & 0.5817 & $3.62(0.51-16.76)$ & $2.82(1.07-5.16)$ & 0.1293 \\
\hline Albumin (gr/L) & $40.5(28-47)$ & $41(28-47)$ & $39(29-44)$ & 0.6151 & $41(28-47)$ & $40(29-44)$ & 0.9078 \\
\hline \multicolumn{8}{|l|}{ Prior therapies, no. (\%) } \\
\hline$\geq 3$ & $23(46)$ & $15(41.67)$ & $8(57.14)$ & 0.3242 & $12(41.38)$ & $11(52.38)$ & 0.4411 \\
\hline Thalidomide & $29(58)$ & $22(61.11)$ & $7(50)$ & 0.4748 & $15(51.72)$ & $14(66.67)$ & 0.2907 \\
\hline Bortezomib & $21(42)$ & $14(38.89)$ & $7(50)$ & 0.4748 & $12(41.38)$ & $9(42.86)$ & 0.9168 \\
\hline ASCT & $40(80)$ & $31(86.11)$ & $9(64.29)$ & 0.1180 & $25(86.21)$ & $15(71.43)$ & 0.2859 \\
\hline \multicolumn{8}{|c|}{ Response to lenalidomide plus dexamethasone, no. (\%) } \\
\hline Responsive & $41(82)$ & $32(88.89)$ & $9(64.29)$ & 0.094 & $28(96.55)$ & $13(61.90)$ & 0.0025 \\
\hline Non-responsive & $9(18)$ & $4(11.11)$ & $5(35.71)$ & & $1(3.45)$ & $8(38.1)$ & \\
\hline \multicolumn{8}{|l|}{ Cytogenetics, no. (\%) } \\
\hline del (13q) & & & & 1.0000 & & & 0.7243 \\
\hline Positive & $13(26)$ & $9(25)$ & $4(28.57)$ & & $7(24.14)$ & $6(28.57)$ & \\
\hline Negative & $37(74)$ & $27(75)$ & $10(71.43)$ & & $22(75.86)$ & $15(71.43)$ & \\
\hline del (17p) & & & & 0.1966 & & & 0.2552 \\
\hline Positive & $8(16)$ & $4(11.11)$ & $4(28.57)$ & & $3(10.34)$ & $5(23.81)$ & \\
\hline Negative & $42(84)$ & $32(89)$ & $10(71.43)$ & & $26(89.66)$ & 16 (76.19) & \\
\hline $\mathrm{t}(4 ; 14)$ & & & & 1.0000 & & & 0.7163 \\
\hline Positive & $9(18)$ & 7 (19.44) & $2(14.29)$ & & $6(20.69)$ & $3(14.29)$ & \\
\hline Negative & $41(82)$ & $29(80.56)$ & $12(85.71)$ & & $23(79.31)$ & 18(85.71) & \\
\hline amp(1q21) & & & & 0.1228 & & & 0.1283 \\
\hline Positive & $20(40)$ & $12(33.33)$ & $8(57.14)$ & & 9 (31.03) & 11 (52.38) & \\
\hline Negative & $30(60)$ & $24(66.67)$ & $6(42.86)$ & & $20(68.97)$ & $10(47.62)$ & \\
\hline
\end{tabular}

and OS (median OS 58.7 vs. 12.1 months, $P<0.0001$ ), whereas the group with both low expression was correlated with shorter PFS (median 4.1 vs. 26.8 months, $P=0.0003$ ) and OS (median 12.1 vs. 46.2 months, $P=0.0002$ ). Of note, high IKZF3 expression appeared associated with higher creatinine but with less lytic lesion, and by multivariable analysis, high IKZF3 expression remained an independent poor risk factor for PFS $(P<0.0001)$ and OS $(P<0.0001)$ after adjusting these two covariates. There was no significant association between IKZF1/3 protein expression and other clinical or biological risk factors (Table 1).

Previous studies have indicated controversial results about the relationship between Ikaros expression level and resistance to lenalidomide. $\mathrm{Lu}$ et al. [7] found that some MM cell lines with higher expressions of IKZF1 or IKZF3 showed resistance to the drug; in contrast, 

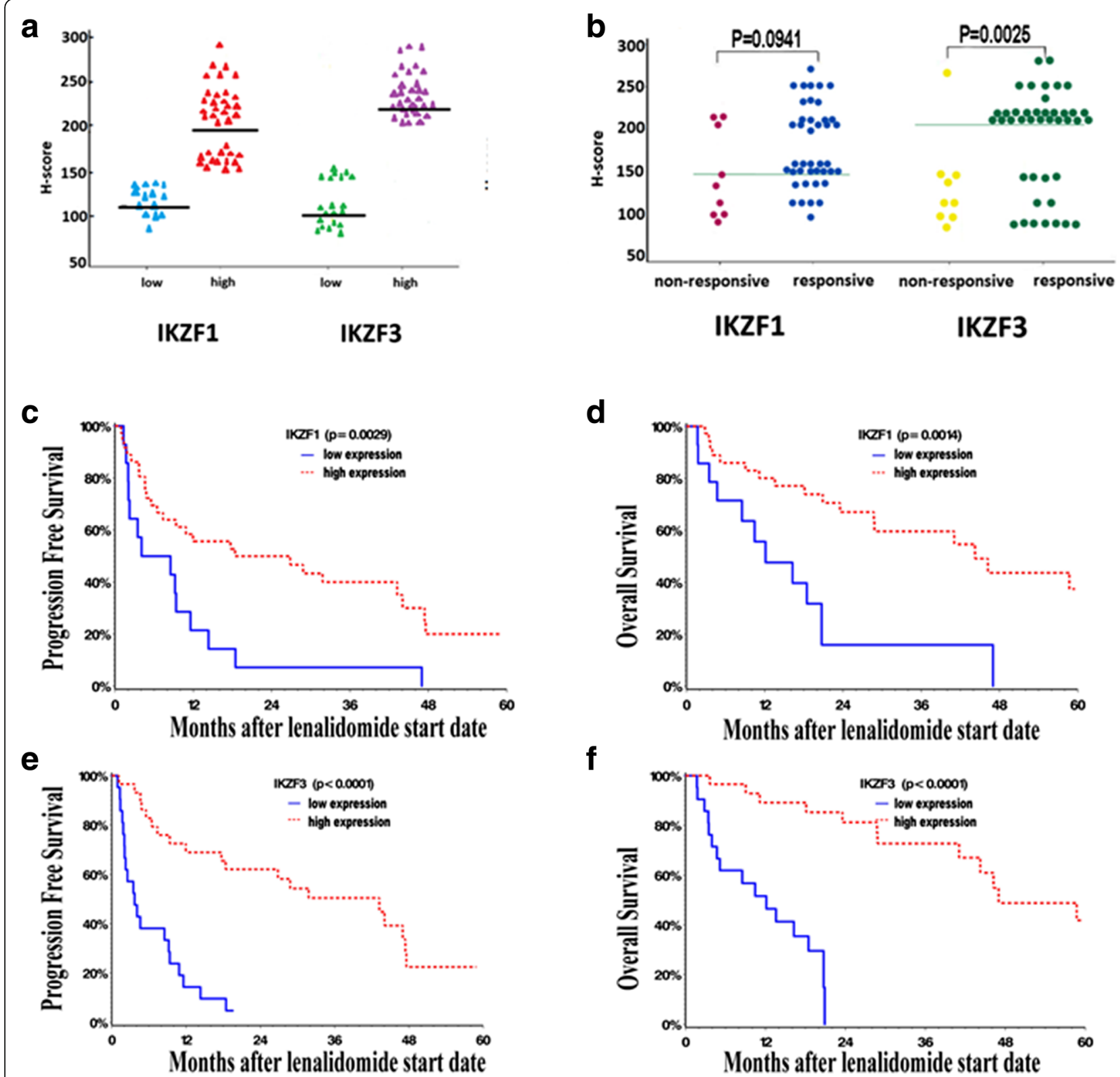

$\mathbf{f}$

Fig. 1 Expression of IKZF1 and IKZF3 proteins in tumor cells, measured by H-score (a) and their correlation with clinical response (b). Progression free survival (PFS) and overall survival (OS) in relation to IKZF1 nuclear expression (c, d), and in relation to IKZF3 nuclear expression (e, f) detected by $\mathrm{IHC}$, respectively

Zhu et al. [8] showed that low IKZF1 transcript levels were correlated with poor response to IMiDs. They also found that higher IKZF1 but not IKZF3 gene expression was associated with better OS. Our study demonstrates that expression of IKZF1/3 proteins (especially IKZF3) is correlated with better outcome in refractory MM patients treated with lenalidomide. A possible explanation for this observation is that in the presence of high IKZF1/3 levels, myeloma cells are more dependent on IKZF-associated signaling for proliferation.
Particularly, IKZF3 is linked to plasma cell development and lenalidomide efficacy as IKZF3 is specifically required for the generation of long-lived plasma cells and it has been shown to be reduced by lenalidomide $[9,10]$.

To the best of our knowledge, this is the first report to show a correlation between IKZF1/3 protein expressions and clinical outcomes in refractory MM treated with lenalidomide. However, this study has limitations as it is retrospective with limited sample size. Nevertheless, as paraffin IHC is routinely available, robust, and inexpensive, if 
confirmed in a larger prospective study, IKZF1/3 (especially IKZF3) immunostaining can be readily adopted in clinical practice for prediction of drug response and clinical outcomes in MM patients receiving lenalidomide therapy.

\section{Additional file}

Additional file 1: Figure S1. Bone marrow biopsy from a patient with MM. (A) H\&E stain, (B) CD138 for myeloma cells, (C) Nuclear expression of IKZF1, (D) Nuclear expression of IKZF3.

\section{Acknowledgements}

Not applicable.

\section{Funding}

The study was supported in part by the grants from Leukemia and Lymphoma Research Society of Canada (LLSC), Cancer Research Society (CRS) and Shanghai Science and Technology International Collaboration Project (No. 15410710300). The funding agencies played no role in the design of the study and collection, analysis, and interpretation of data and in writing the manuscript.

\section{Availability of data and materials}

Please contact author for data requests.

\section{Authors' contributions}

MP and MB carried out the experiments. MP drafted the manuscript. EA performed the statistical analysis. $\mathrm{JH}$ participated in design the study. DR contributed to patient clinical data and sample collections. HC conceived of the study, participated in its design and coordination, and helped to draft the manuscript. All authors read and approved the final manuscript.

\section{Competing interests}

D.R. is a consultant/advisory role for Celgene. All remaining authors declare no competing interests.

\section{Consent for publication}

NA.

\section{Ethics approval and consent to participate}

The study was approved by Research Ethic Board of University Health Network (UHN): Identification of Novel Prognostic Markers in Multiple Myeloma. 05-0573-TE.

\section{Author details}

'Department of Laboratory Medicine and Pathobiology, University of Toronto, Toronto, Canada. ${ }^{2}$ Department of Biostatistics, University of Toronto, Toronto, Canada. ${ }^{3}$ Department of Hematology and Medical Oncology, University of Toronto, Toronto, Canada. ${ }^{4}$ Department of Hematology, Shanghai Chang Zheng Hospital, Shanghai, China. ${ }^{5}$ Department of Laboratory Hematology, University Health Network, 200 Elizabeth Street, 11E-413, Toronto, ON M5G 2C4, Canada.

Received: 16 September 2016 Accepted: 3 November 2016 Published online: 14 November 2016

\section{References}

1. Krönke J, Udeshi ND, Narla A, Grauman P, Hurst SN, McConkey M, Svinkina T, Heckl D, Comer E, Li X, Ciarlo C, Hartman E, Munshi N, Schenone M, Schreiber SL, Carr SA, Ebert BL. Lenalidomide causes selective degradation of IKZF1 and IKZF3 in multiple myeloma cells. Science. 2014;343(6168):301-5.

2. Chamberlain PP, Lopez-Girona A, Miller K, Carmel G, Pagarigan B, Chie-Leon B, Rychak E, Corral LG, Ren YJ, Wang M, Riley M, Delker SL, Ito T, Ando H, Mori T, Hirano Y, Handa H, Hakoshima T, Daniel TO, Cathers BE. Structure of the human cereblon-DDB1-lenalidomide complex reveals basis for responsiveness to thalidomide analogs. Nat Struct Mol Biol. 2014;21(9):803-9.

3. Bjorklund CC, Lu L, Kang J, Hagner PR, Havens CG, Amatangelo M, Wang M, Ren Y, Couto S, Breider M, Ning Y, Gandhi AK, Daniel TO, Chopra R, Klippel A, Thakurta AG. Rate of CRL4(CRBN) substrate Ikaros and Aiolos degradation underlies differential activity of lenalidomide and pomalidomide in multiple myeloma cells by regulation of c-Myc and IRF4. Blood Cancer J. 2015;5:e354.

4. Shaffer AL, Emre NC, Lamy L, Ngo VN, Wright G, Xiao W, Powell J, Dave S, Yu X, Zhao H, Zeng Y, Chen B, Epstein J, Staudt LM. IRF4 addiction in multiple myeloma. Nature. 2008;454(7201):226-31.

5. Fink EC, Ebert BL. The novel mechanism of lenalidomide activity. Blood. 2015;126(21):23669.

6. Yang $Y$, Shaffer AL, Emre NC, Ceribelli M, Zhang M, Wright G, Xiao W, Powell J, Platig J, Kohlhammer H, Young RM, Zhao H, Yang Y, Xu W, Buggy JJ, Balasubramanian S, Mathews LA, Shinn P, Guha R, Ferrer M, Thomas C, Waldmann TA, Staudt LM. Exploiting synthetic lethality for the therapy of ABC diffuse large B cell lymphoma. Cancer Cell. 2012;21(6):723-37.

7. Lu G, Middleton RE, Sun H, Naniong M, Ott CJ, Mitsiades CS, Wong KK, Bradner JE, Kaelin Jr WG. The myeloma drug lenalidomide promotes the cereblondependent destruction of Ikaros proteins. Science. 2014;343(6168):305-9.

8. Zhu YX, Braggio E, Shi CX, Kortuem KM, Bruins LA, Schmidt JE, Chang XB, Langlais P, Luo M, Jedlowski P, LaPlant B, Laumann K, Fonseca R, Bergsagel PL, Mikhael J, Lacy M, Champion MD, Stewart AK. Identification of cereblonbinding proteins and relationship with response and survival after IMiDs in multiple myeloma. Blood. 2014;124(4):536-45.

9. Jourdan $M$, Cren $M$, Schafer $P$, Robert $N$, Duperray $C$, Vincent $L$, Ceballos $P$, Cartron G, Rossi JF, Moreaux J, Chopra R, Klein B. Differential effects of lenalidomide during plasma cell differentiation. Oncotarget. 2016. doi:10. 18632/oncotarget.8581.

10. Cortés M, Georgopoulos K. Aiolos is required for the generation of high affinity bone marrow plasma cells responsible for long-term immunity. J Exp Med. 2004;199(2):209-19.
Submit your next manuscript to BioMed Central and we will help you at every step:

- We accept pre-submission inquiries

- Our selector tool helps you to find the most relevant journal

- We provide round the clock customer support

- Convenient online submission

- Thorough peer review

- Inclusion in PubMed and all major indexing services

- Maximum visibility for your research

Submit your manuscript at www.biomedcentral.com/submit
Biomed Central 